\title{
Design and synthesis of a cyclitol-derived scaffold with axial pyridyl appendages and its encapsulation of the silver(I) cation
}

\author{
Pierre-Marc Léo, Christophe Morin * and Christian Philouze
}

\section{Letter}

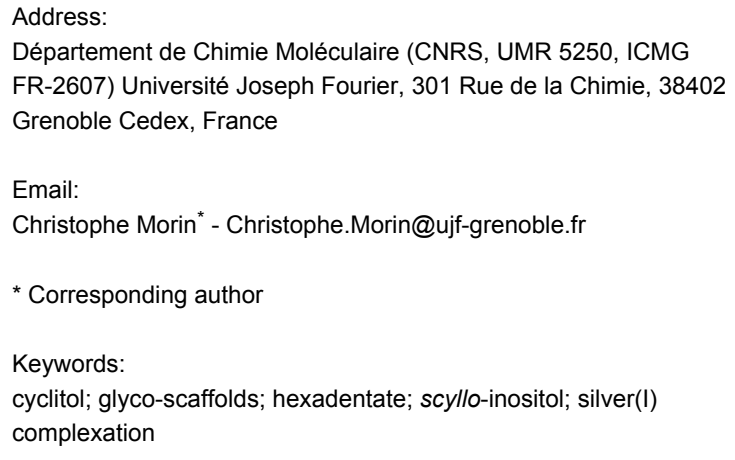

\author{
Beilstein J. Org. Chem. 2010, 6, 1022-1024 \\ doi:10.3762/bjoc. 6.115 \\ Received: 01 July 2010 \\ Accepted: 18 October 2010 \\ Published: 29 October 2010 \\ Guest Editor: T. K. Lindhorst \\ (c) 2010 Léo et al; licensee Beilstein-Institut. \\ License and terms: see end of document.
}

\begin{abstract}
Conversion of a myo-inositol derivative into a scyllo-inositol-derived scaffold with $C_{3 v}$ symmetry bearing three axial pyridyl appendages is presented. This pre-organized hexadentate ligand allows complexation of silver(I). The crystal structure of the complex was established.
\end{abstract}

\section{Introduction}

Despite its recognized potential for nuclear medicine applications [1], the $\beta^{-}$emitter ${ }^{111} \mathrm{Ag}\left(t_{1 / 2}=7.47 \mathrm{~d}\right)$, which can be produced carrier-free and with high specific activity [2,3], has not yet found widespread uses [4,5]. This is due in part to the lack of suitable Ag complexing agents and in this work the synthesis of an cyclitol-derived scaffold designed to sequester $\mathrm{Ag}$ is presented. Interaction of myo-inositol-derived podands [6] and crown ethers [7] with Ag salts has been shown to depend on the relative spatial orientation of the binding sites moreover, in mono-orthoesters of scyllo-inositol the three axial hydroxy groups can be used to link substituents in a pre-organized manner [8-10]. Thus the introduction of pyridine groups (known to bind $\mathrm{Ag}(\mathrm{I})$ efficiently [11-14]) on a scyllo-inositol orthoester was considered, which led to the design of scaffold $\mathbf{1}$ (Figure 1). Indeed, upon complexation with participation of three oxygen atoms in the binding, no substantial rearrangement of this semi-rigid structure is to be expected. In addition, reductive cleavage of one of the ortho-ester $\mathrm{C}-\mathrm{H}$ benzylic bonds, which is known to yield a free hydroxy group [15,16], would allow ligation of this scaffold.

\section{Results and Discussion Chemistry}

The synthesis of $\mathbf{1}$ was accomplished in 6 steps from the readily available myo-inositol orthobenzoate (2) [17] (Figure 2). As scyllo-inositol derivatives are derived from $m y o$-inositols by an 


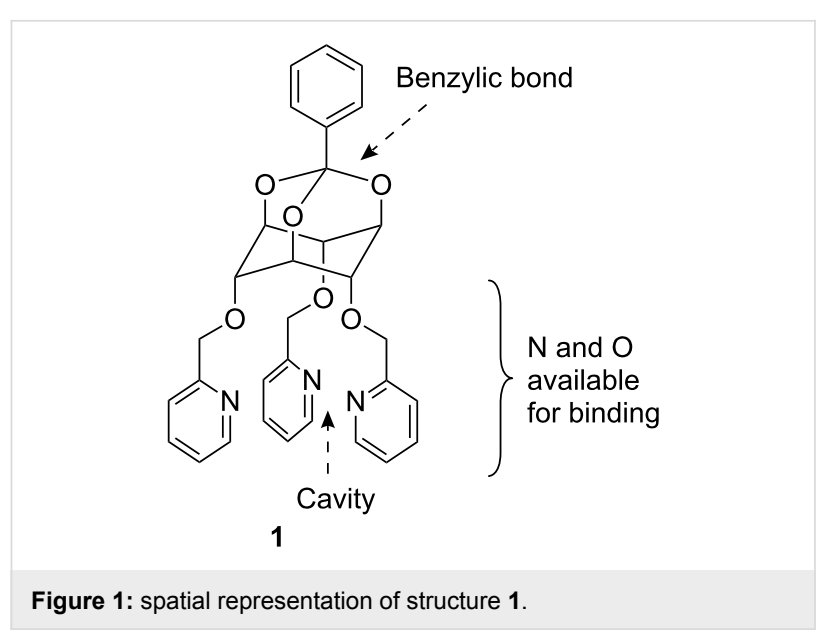

oxidation/reduction sequence $[8,18,19]$, selective protection (tert-butyldimethylsilyl chloride, 2,6-lutidine, DMF, $80{ }^{\circ} \mathrm{C}, 2$ days) of the equatorial hydroxy group of $\mathbf{2}$ was first performed, to give the silyl ether 3 (70\%) and subsequent picolylation (NaH, 2-picolyl chloride, DMF) of the remaining free hydroxy groups gave 4 (65\%). The equatorial hydroxy group then was deblocked (tetrabutylammonium fluoride in THF) to afford $\mathbf{5}$ (86\%). Inversion of configuration was accomplished via Swern oxidation [20] to furnish ketone $6(95 \%)$, which was then reduced $\left(\mathrm{NaBH}_{4}, \mathrm{CH}_{3} \mathrm{OH}\right)$ to $7(99 \%)$. Although a configurational assignment did not prove possible from ${ }^{1} \mathrm{H}$ NMR data (in epimers 5 and $\mathbf{7}$ the dihedral angles of the proton geminal to the hydroxy group with vicinal protons are similar), the ${ }^{1} \mathrm{H}$ - and ${ }^{13} \mathrm{C}$ NMR spectra of 7 clearly differ from those of its epimer. Compounds 5 and 7 were also acetylated (to 8 and $\mathbf{9}$, respectively) and the chemical shift of the acetyl methyl group of 9 $(\delta=1.7 \mathrm{ppm})$ displayed an upfield shift compared to that of 8 $(\delta=2.1 \mathrm{ppm})$ due to ring-current effects from through-space interactions with the pyridyl groups. That a scyllo-inositol derivative had been obtained was confirmed after the introduction of the third pyridyl group ( $\mathrm{NaH}, 2$-picolyl chloride). In the resulting tri-picolyl derivative $\mathbf{1}(71 \%)$ a $C_{3 v}$ axis of symmetry is now present, which leads to simplification of NMR spectra. The structure of 1 was subsequently confirmed (see below) by $\mathrm{X}$-ray diffraction of a single crystal of its Ag-complex.

\section{Complexation}

Incremental addition of silver(I) trifluoromethanesulfonate to a solution of 1 in 1:1 $\mathrm{CD}_{3} \mathrm{OD} / \mathrm{CDCl}_{3}$ was monitored by NMR. A single set of resonances was observed at all concentrations. That the pyridine rings and the "oxygenated cavity" were involved in silver binding was shown by the relevant shifts in both the ${ }^{1} \mathrm{H}$ and ${ }^{13} \mathrm{C}$-NMR spectra (see Supporting Information File 1). However, in the absence of characteristic signals for $\mathrm{Ag}(\mathrm{I})$ complex (even at low temperature: $-50{ }^{\circ} \mathrm{C}$ ) NMR methods cannot be used for the determination of the complex stability

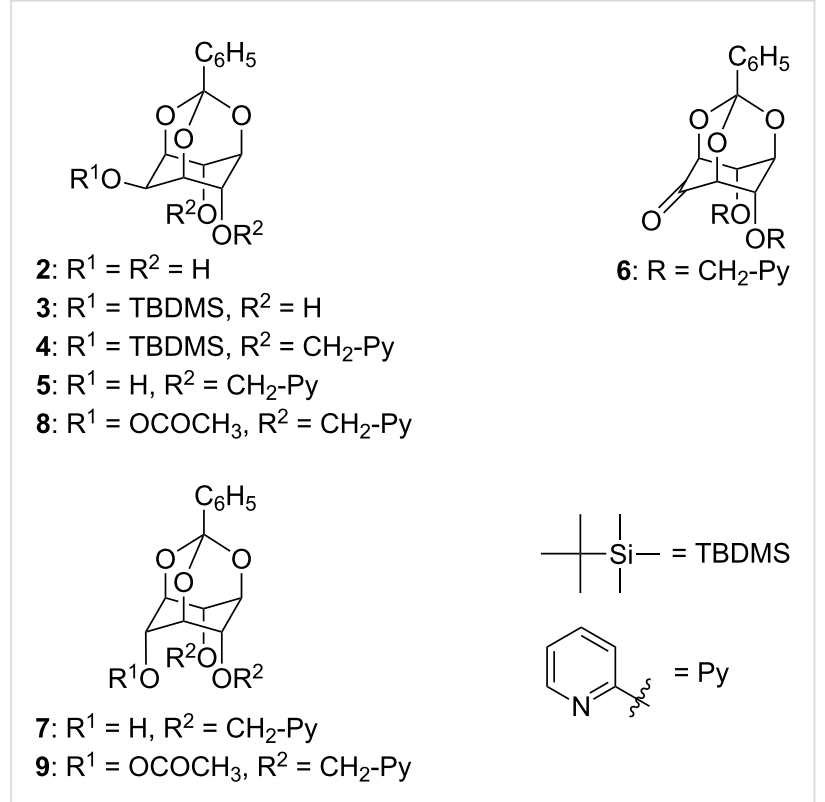

Figure 2: structures of compounds 2-9.

constant. The electrospray mass spectrum (from the very solution contained in the NMR tube) revealed a 1:1 complex, with the expected ${ }^{107} \mathrm{Ag} /{ }^{109} \mathrm{Ag}$ isotopic ratio. The stability constant of the complex could be determined by spectrophotometric titration, which was carried out in 1:1 aqueous methanol (the complex is not water soluble) and its value $\left(\log K_{1} \cdot \mathrm{Ag}=3.8 \pm\right.$ 0.2 ) is in agreement with that of a previously described $\mathrm{Ag}(\mathrm{I})$ complex in a $\mathrm{N}_{3} \mathrm{O}_{3}$ environment [13].

Study of the molecular structure of the complex was made possible as a single crystal could be grown by slow evaporation of a methanol/ethanol solution of stoichiometric amounts of $\mathbf{1}$ and silver trifluoromethanesulfonate. The complex crystallises in the triclinic system, with a pseudo-ternary axis of symmetry. Its coordination sphere involves all 3 nitrogen atoms as well as the 3 oxygen atoms which are implied in the linkage of the pyridines (Figure 3). Bond distances and angles (see Supporting Information File 1) are in accord with those of known silver complexes which are hexa-coordinated with pyridyl groups and oxygen atoms $[13,14]$.

\section{Conclusion}

A rigid scaffold with $C_{3 v}$ symmetry bearing three appendages in a pre-organized manner, 1 , could be synthesized in 6 steps from myo-inositol orthobenzoate and in $25 \%$ overall yield. Noteworthy is that the synthetic scheme may allow variation of heterocyclic substituents, which need not be the same since they are introduced at different stages of the synthesis. The complex formed with silver cation $\left(\log K_{1 \cdot A g}=3.8 \pm 0.2\right)$ was shown to involve $\mathrm{N}_{3} \mathrm{O}_{3}$ coordination with the $\mathrm{Ag}(\mathrm{I})$ ion lying within the 


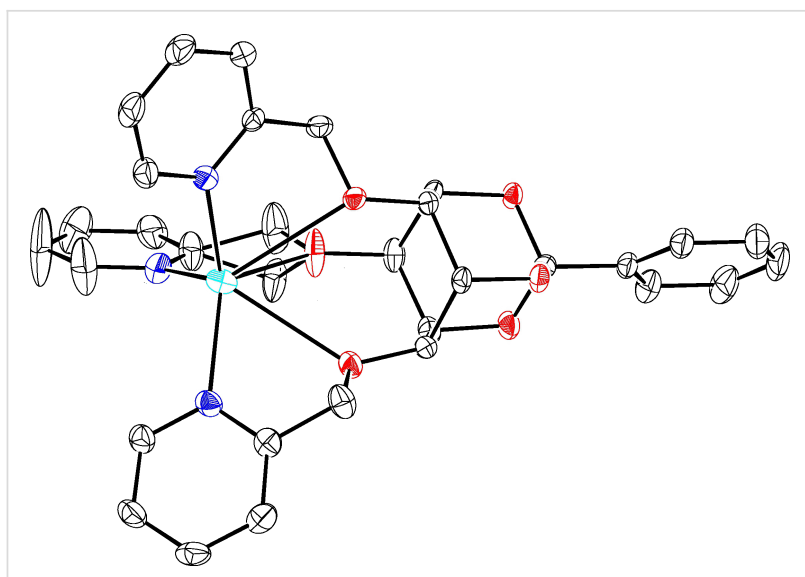

Figure 3: ORTEP drawing for the 1·Ag(I) cation complex (ellipsoids are drawn at the $50 \%$ probability level and $\mathrm{H}$ atoms are omitted for clarity).

cage. However, the complex is not water soluble (which precludes its use for biomedical applications) although the grafting of hydrophilic appendages to aromatic residues could increase its hydrophilicity.

\section{Supporting Information}

Supporting Information features experimental procedures,

${ }^{1} \mathrm{H}$ NMR and ${ }^{13} \mathrm{C}$ NMR spectra; electrospray mass spectrum and the crystal structure of the Ag complex.

\section{Supporting Information File 1}

Synthesis and characterisation data for compounds 1-9 and $\mathbf{1} \cdot \operatorname{Ag}(\mathrm{I})$.

[http://www.beilstein-journals.org/bjoc/content/ supplementary/1860-5397-6-115-S1.pdf]

\section{Acknowledgements}

The help of Corinne Bailly (CDC-Cambridge database searching), Catherine Belle (spectrophotometry), Béatrice Gennaro (low-temperature NMR experiments) and Guy Serratrice (spectrophotometry) is gratefully acknowledged.

\section{References}

1. Alberto, R.; Schubiger, P. A. Recent Res. Dev. Inorg. Chem. 1998, 1, 73-89.

2. Alberto, R.; Bläuenstein, P.; Novak-Hofer, I.; Smith, A.; Schubiger, P. A. Int. J. Radiat. Appl. Instrum., Part A 1992, 43, 869-872. doi:10.1016/0883-2889(92)90148-8

3. Das, N. R.; Banerjee, S.; Chatterjee, K.; Lahiri, S. Appl. Radiat. Isot. 1999, 50, 643-647. doi:10.1016/S0969-8043(98)00115-8

4. Kaden, T. A. Dalton Trans. 2006, 3617-3623. doi:10.1039/b606410h
5. Chatopadhyay, S.; Vilmanath, K. V.; Saha, S.; Korde, A.; Sarma, H. D.; Pal, S.; Das, M. K. Appl. Radiat. Isot. 2008, 66, 334-339. doi:10.1016/j.apradiso.2007.09.003

6. Sureshan, K. M.; Shashidhar, M. S.; Varma, A. J. J. Chem. Soc., Perkin Trans. 2 2001, 2298-2302. doi:10.1039/b106717f

7. Sureshan, K. M.; Shashidhar, M. S.; Varma, A. J. J. Org. Chem. 2002 , 6884-6888. doi:10.1021/jo025783g

8. Lee, H. W.; Kishi, Y. J. Org. Chem. 1985, 50, 4402-4404. doi:10.1021/jo00222a046

9. Tse, B.; Kishi, Y. J. Am. Chem. Soc. 1993, 115, 7892-7893. doi:10.1021/ja00070a051

10. Lee, N.-Y.; Jang, W.-J.; Yu, S.-H.; Im, J.; Chung, S.-K. Tetrahedron Lett. 2005, 46, 6063-6066. doi:10.1016/j.tetlet.2005.07.001

11. Inokuma, S.; Sakai, S.; Katoh, R.; Nishimura, J. Bull. Chem. Soc. Jpn. 1994, 67, 1462-1467. doi:10.1246/bcsj.67.1462

12. Lamb, J. D.; Nazarenko, A. Y.; Uenishi, J.; Tsukube, H. Anal. Chim. Acta 1998, 373, 167-173. doi:10.1016/S0003-2670(98)00360-2

13. Danil de Namor, A. F.; Piro, O. E.; Pulcha Salazar, L. E.; Aguilar-Cornejo, A. F.; Al-Rawi, N.; Castellano, E. E.; Sueros Velarde, F. J. J. Chem. Soc., Faraday Trans. 1998, 94, 3097-3104. doi:10.1039/a805430d

14. Bowmaker, G. A.; Effendy; Lim, K. C.; Skelton, B. W.; Sukarianingsih, D.; White, A. H. Inorg. Chim. Acta 2005, 358, 4342-4370. doi:10.1016/j.ica.2005.04.008

15. Honda, T.; Endo, K.; Ono, S. Chem. Pharm. Bull. 2000, 48, 1545-1548.

16. Murali, C.; Shashidhar, M. S.; Gopinath, C. S. Tetrahedron 2007, 63, 4149-4155. doi:10.1016/j.tet.2007.02.096

17. Bhosekar, G.; Murali, C.; Gonnade, R. G.; Shashidhar, M. S.; Bhadbhade, M. M. Cryst. Growth Des. 2005, 5, 1977-1982. doi:10.1021/cg050272j

18. Shashidhar, M. S. ARKIVOC 2002, vii, 63-75.

19. Sureshan, K. M.; Shashidhar, M. S.; Praveen, T.; Das, T. Chem. Rev. 2003, 103, 4477-4504. doi:10.1021/cr0200724

20. Tidwell, T. T. Org. React. 1990, 39, 297-572.

\section{License and Terms}

This is an Open Access article under the terms of the Creative Commons Attribution License (http://creativecommons.org/licenses/by/2.0), which permits unrestricted use, distribution, and reproduction in any medium, provided the original work is properly cited.

The license is subject to the Beilstein Journal of Organic Chemistry terms and conditions: (http://www.beilstein-journals.org/bjoc)

The definitive version of this article is the electronic one which can be found at: doi:10.3762/bjoc.6.115 